\title{
The Hawaiian cave planthoppers (Homoptera: Fulgoroidea: Cixiidae) - A model for rapid subterranean speciation?
}

\author{
Hannelore Hoch *
}

\begin{abstract}
SUMMARY
After the successful colonization of a single ancestral species in the Hawaiian Islands, planthoppers of the cixiid genus Oliarus underwent intensive adaptive radiation resulting in 80 described endemic species. Oliarus habitats range from montaneous rain forests to dry coastal biotopes and subterranean environments. At least 7 independant evolutionary lines represented by different species have adapted to lava tubes on Molokai (1), Maui (3), and Hawaii Island (3). Behavioral and morphological studies on one of these evolutionary lines on Hawaii Island, the blind, flight- and pigmentless Oliarus polyphemus have provided evidence for reproductive isolation between allopatric populations which may in fact be separate species. Significant differences in song parameters were observed even between populations from neighbouring lava tubes, although the planthoppers are capable of underground migration through the voids and cracks of the mesocavernous rock system which is extant in young basalt: after a little more than 20 years, lava tubes within the Mauna Ulu 1974 flow had been colonized by $O$. "polyphemus" individuals, most probably originating from a near-by forestkipuka. Amazingly, this species complex is found on the youngest of the Hawaiian Islands, with probably less than 0.5 m.y., which suggests rapid speciation processes. Field observations have led to the development of a hypothesis to match underground speciation with the dynamics of vegetational succession on the surface of active volcanoes. Planthopper range partitioning and geographic separation of populations by young lava flows, founder events and small population size may be important factors involved in rapid divergence.
\end{abstract}

\section{INTRODUCTION}

One of the central questions in evolutionary biology is the formation of new species. It has been shown that mating behavior plays a key role in the process of speciation, especially in regard to intraspecific communication (Otte, 1989). To guarantee reproductive success it is essential for conspecific individuals of the different sexes to recognize each other as potential partners. Mobile, sexually reproducing organisms have developed specific be-

* Institut für Systematische Zoologie, Museum für Naturkunde, Humboldt Universität Berlin, Berlin, Germany.

Paper presented at the Symposium "Cave Insects and Evolution", organised by M. Bologna and F.G. Howarth, for the XX International Congress of Entomology, Firenze, Italy, August 25-31, 1996. 
havioral patterns which serve to bring together males and females of the same species for mating. Each species is characterized by a specific mate recognition system (SMRS) which consists of chemical, optical, tactile and acoustic signals, or a combination thereof (Paterson 1981; 1985). If by any reason the SMRS of two populations diverge to a point where individuals of the different sexes no longer recognize each other as mating partners, i.e., courtship behavior is not initiated and therefore successful matings are no longer possible, these populations are reproductively isolated, and thus have reached the status of biological species.

One of the difficulties one faces when studying the formation of new species in natural populations is that the very process of speciation is gradual and thus withdrawn from direct observation. "Most of the speciational situations with which we deal will already be stabilized, optimized states, with the appropriate evolutionary adjustments having already occured, so that only the successful systems are available for study. Indeed, it may require a great deal of good fortune to encounter dynamic evolution of a biocommunicative system in natural populations" (Littlejohn, 1988).

A nearly ideal system to study incipient speciation is provided by the cavernicolous insects from Hawaii. Due to its isolated geographic position in the mid of the Pacific, comparatively few plant- and animal species have originally reached the islands (Howarth, 1991). The descendants of those species which successfully colonized the islands in the course of many generations adapted to a large variety of habitats and gave rise to speciose and ecologically diverse lineages: Hawaii is especially well-known for examples of adaptive radiation in flowering plants (e.g., Carr, 1987), surfacedwelling insects (e.g., Hardy, 1974), and birds (Freed et al., 1987). Howarth (1972) demonstrated that adaptive radiation is not restricted to surface habitats by discovering a remarkable rich and diverse obligately cavernicolous (troglobitic) arthropod fauna.

An important element of the Hawaiian cave fauna are cixiid planthoppers of the genus Oliarus. Epigean Oliarus species (Fig. 1) are represented with 80 named taxa (56 species and 24 subspecies) on the main islands, occurring in nearly all vegetation zones where they suck sap from living plants. All Hawaiian Oliarus species are endemic to Hawaii and most likely are descendants of one primary colonizing species. Within Oliarus, at least 7 independant evolutionary lineages have undergone an adaptive shift (Howarth, 1983) to subterranean habitats: 1 on Molokai, 3 on Maui, and 3 on the Island of Hawaii (Hoch and Howarth, unpublished data). One of the lineages that have invaded caves on the Island of Hawaii is Oliarus polyphemus Fennah (Fig. 2), a highly troglomorphic, blind, flight- and pigmentless species. Within the cave ecosystem, $O$. polyphemus is a rhizophagous primary consumer, sucking sap from 
roots of the native tree Metrosideros polymorpha (Myrtaceae) in a perpetually dark, warm and moisture-saturated environment (Fig. 3). It should be noted that the primary habitat of this species not only comprises underground spaces sufficiently large for humans to enter ("caves"), but also an interconnecting system of voids and cracks $(0.1-20 \mathrm{~cm}$ in width, Howarth, 1983) which is common in young basalt. Thus, caves are but a window to the mesocavernous rock system (MSS, milieu souterrain superficiel, Juberthie, 1983) where similar conditions prevail.

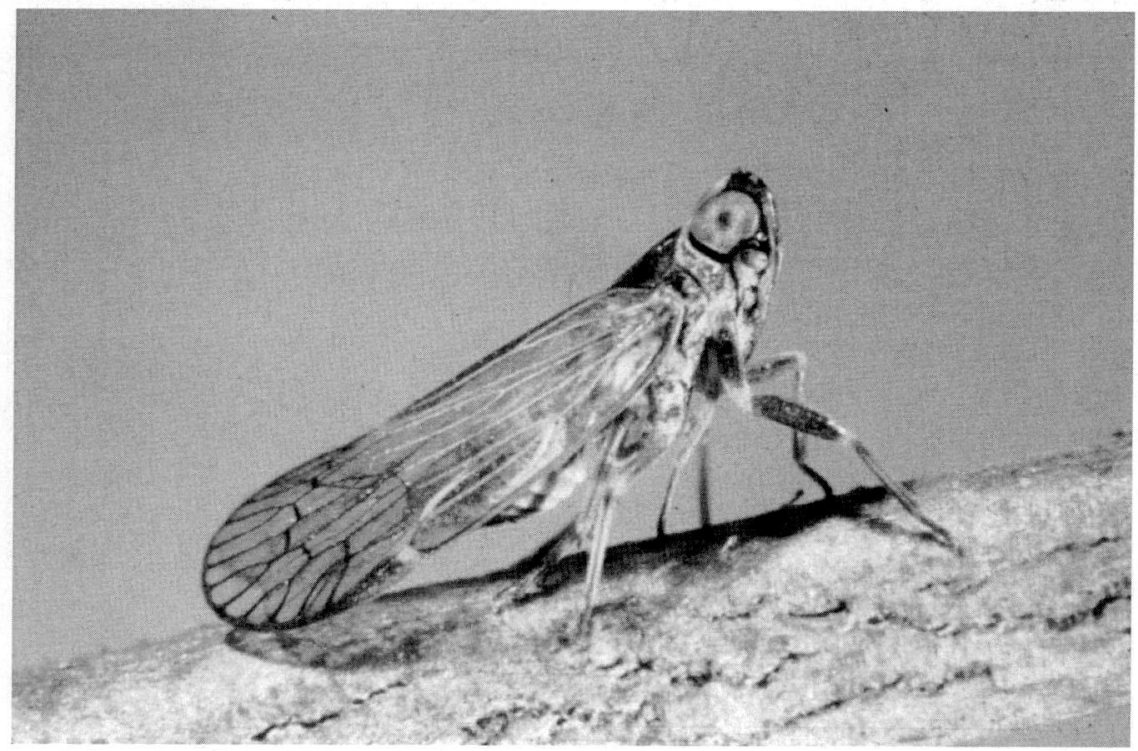

Fig. 1 - Epigean Oliarus species.

The SMRS of cavernicolous planthoppers

Preliminary studies (Howarth et al., 1990) had shown that cavernicolous planthoppers - like their epigean relatives - communicate by lowfrequency substrate-borne vibrational signals which are produced by a specialized organ in the insects' first two abdominal segments (Ossiannilsson, 1949). In several studies on epigean planthoppers it had been shown that these signals play a key role in species recognition and are species-specific (Claridge, 1985).

In cave-dwelling planthoppers, these vibratory signals are pivotal for the recognition and location of a potential conspecific mate, since in the cave environment no optical clues are available to the insect, and chemical 
communication, e.g., by pheromones is not known in the Fulgoroidea (Hoch and Howarth, 1993). In a field experiment, we demonstrated that living roots are especially well suited for transmission of vibratory signals (Hoch and Howarth, 1993).

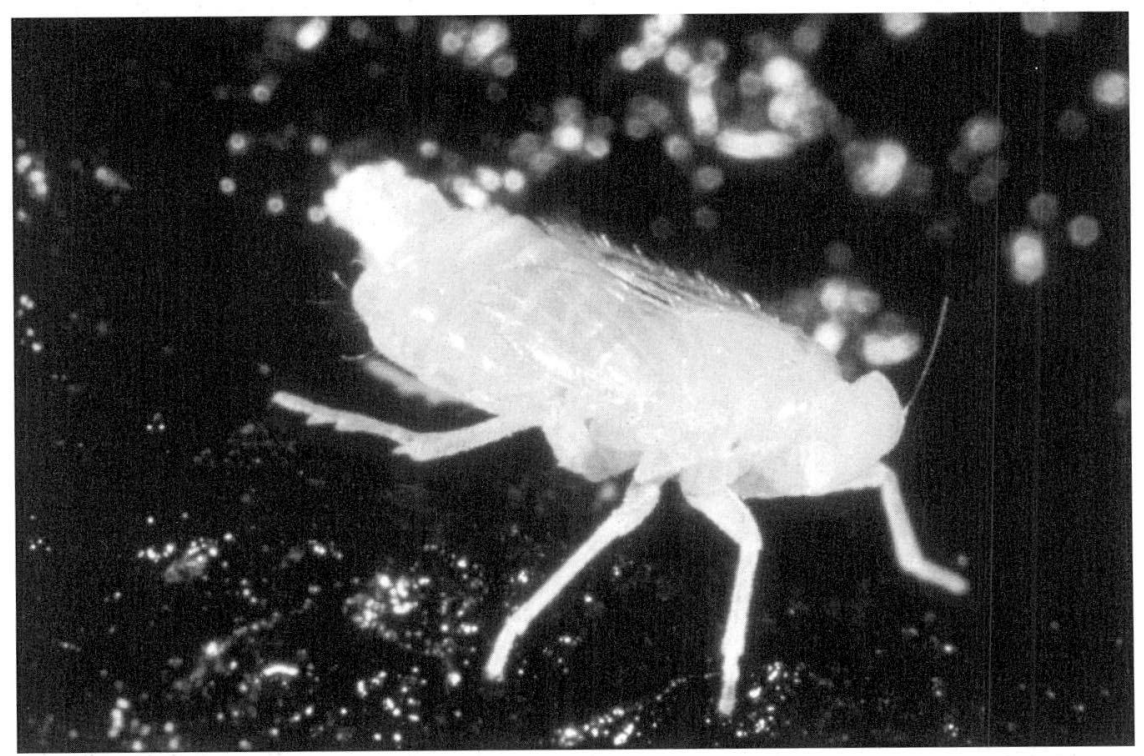

Fig. 2 - Oliarus polyphemus (female).

Evolutionary dynamics of behavioral divergence among O. polyphemus populations

Previously, O. polyphemus had been regarded a single, widespread species, with morphologically nearly identical populations occuring in similar habitats in numerous lava tubes within Mauna Loa, Mauna Kea, Hualalai and Kilauea volcanic systems. Our study on mating behavior of $7 \mathrm{O}$. polyphemus populations revealed the following results (Hoch and Howarth, 1993):

1. Communication signals consisted of more or less homogenous pulse trains arranged in time/amplitude-modulated patterns.

2. Variation of call pattern and single call parameters within a population was comparatively low, with male and female calls resembling each other.

3. Variation of call pattern and single call parameters between populations was high in both sexes, in some cases even differing significantly.

4. Playback-experiments using individuals from different populations provided evidence that individuals of a given population responded prefe- 


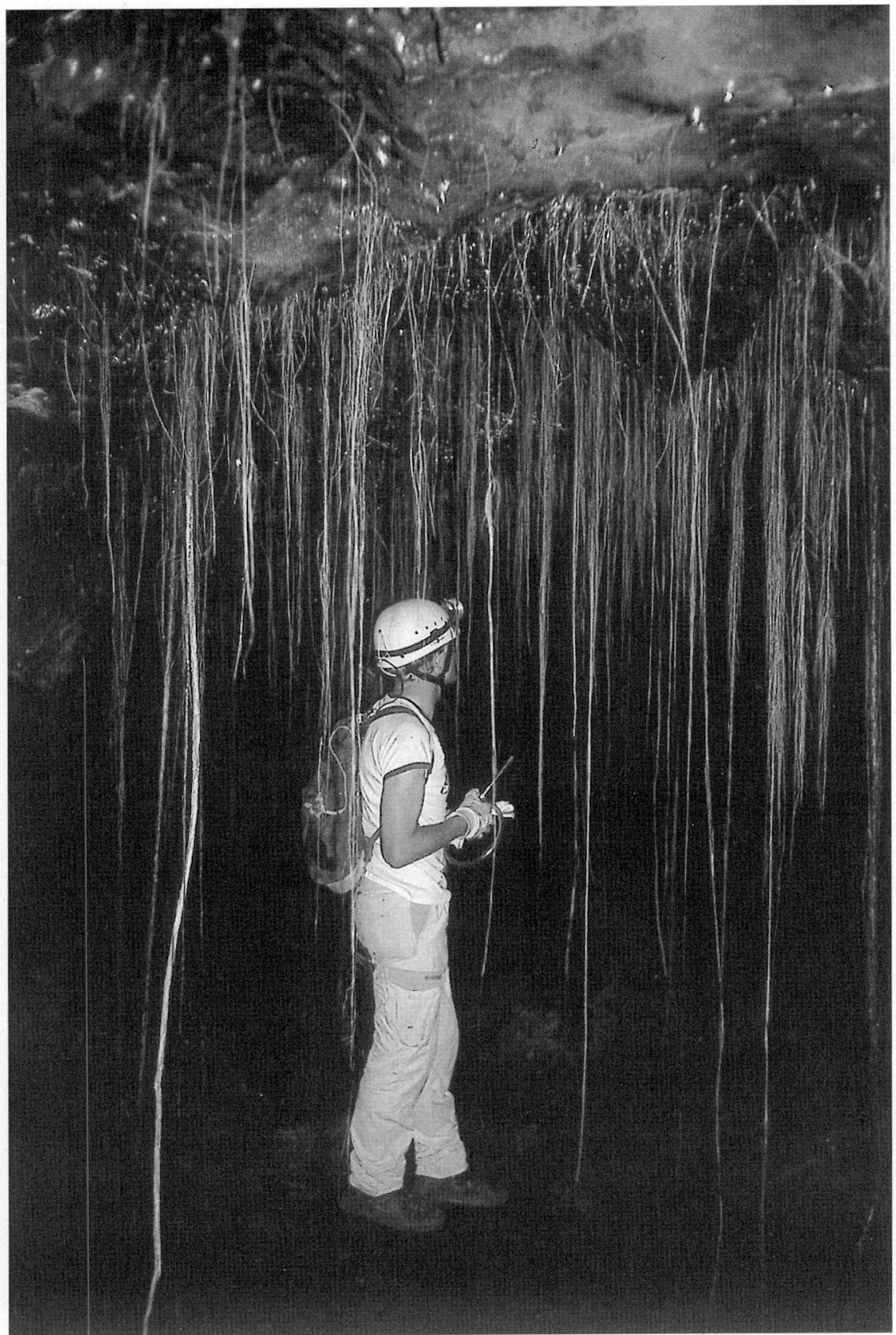

Fig. 3 - Interior of a lava tube with root curtains of Metrosideros polymorpha. 
rably to an opposite-sex individual from that same population, whereas individuals from different populations did apparently not recognize each other as potential mates, and courtship behavior was not initiated.

These results suggest that $O$. polyphemus has to be regarded not as a single, widespread species but rather as a complex of morphologically similar and most probably closely related, yet separate, i.e. reproductively isolated, species. Since so far only a few populations were studied, it is completely unclear of how many biological species " $O$. polyphemus" consists. It is remarkable that even between populations from caves which are only a few kilometers apart, there is no indication of genetic exchange - this would be easily conceivable considering the possibilities of underground migration of these small insects via the mesocavernous rock system.

Does active volcanism promote speciation in obligately cavernicolous planthoppers?

How can we explain the observed divergence of a cavernicolous organism on one island within a comparatively short span of time? According to recent estimates, Hawaii Island is less than 400,000 years old. Keeping in mind that this oceanic island had to be colonized by higher plants first to support subsequently colonizing insects species, we can assume that time available for the evolution of cave-adapted species was even much less than that. A key to understanding of the evolutionary processes which are underlying the observed pattern may be found in the geology and vegetation dynamics on active volcanoes. Recent radiocarbon-dating of ash layers and lava flows of Mauna Loa have shown that the surface of this volcano is renewed at a rate of ca. $40 \%$ in 1,000 years (Holcomb, 1987; Lockwood and Lipman, 1987). For Kilauea, today the most active volcano on Hawaii Island, these estimates may even be too low. Own field studies have shown that the primary habitat of $O$. "polyphemus" is characterized by a specific stage in the succession of surface vegetation: in the field, this stage is characterized by sparse vegetation cover consisting of species pioneering on new lava flows, e.g., Sadleria and Cibotium ferns, and Metrosideros (Fig. 4). This stage is intermediate in the succession of vegetation on new lava flows: from completely unvegetated areas to the formation of a dense forest cover. This "intermediate" stage of vegetational succession provides ideal conditions for cave planthoppers: on the surface, the still sparsely vegetated flow is comparatively dry and soil development not far progessed. Colonizing plants thus produce large quantities of long roots which penetrate the porous rock to utilize percolating water. Lava tubes underneath these formations usually house large Oliarus populations. Over time, 


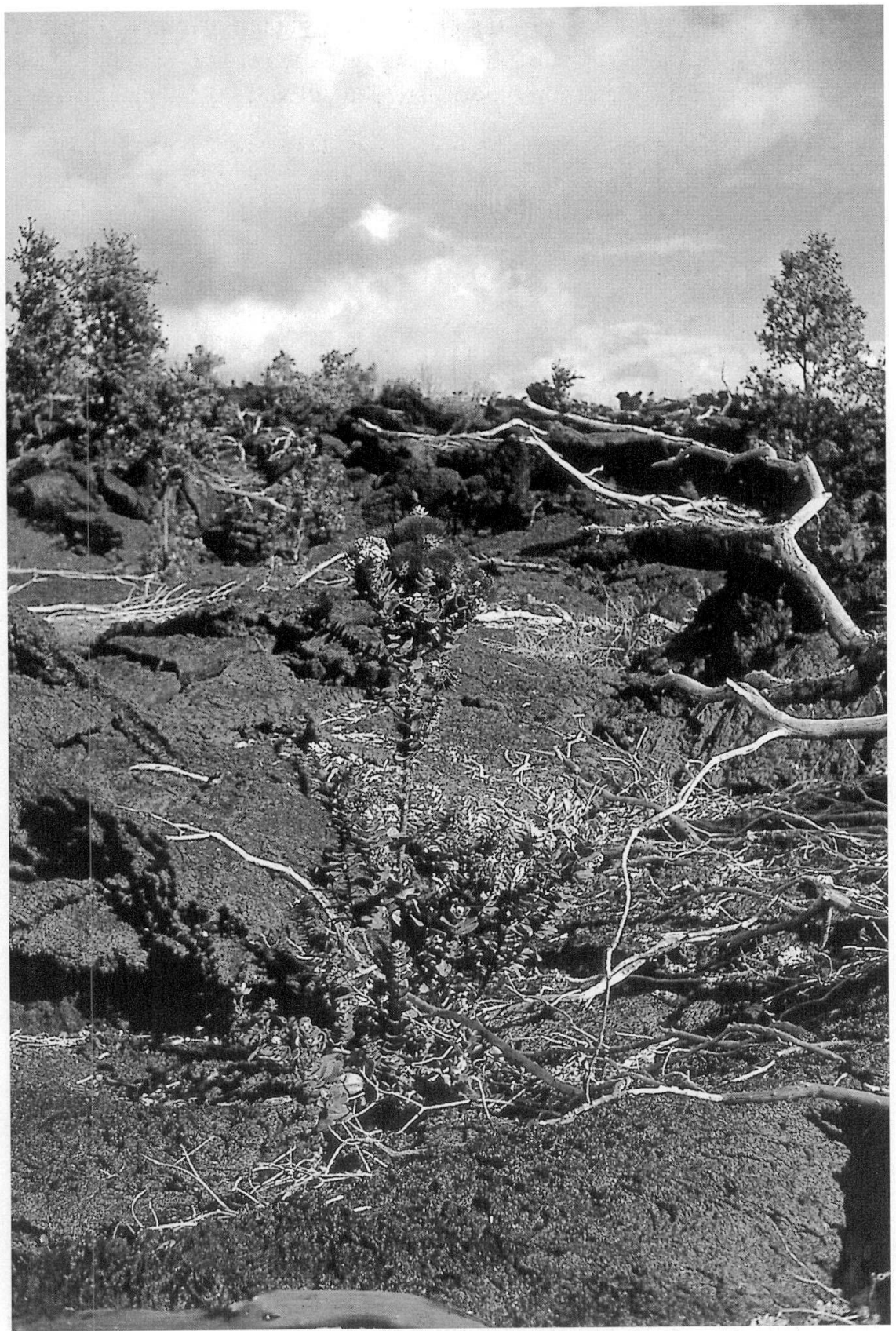

Fig. 4 - Metrosideros polymorpha colonizing a young lava field. 
progressive succession and erosion lead to the development of a soil layer, which will eventually support a dense forest cover. In these areas, roots are concentrating inside the absorbing soil layer. Field observations revealed that lava tubes underneath densely vegetated flows usually show sparse root development and consequently, $O$. "polyphemus" individuals are rarely seen. On active volcanoes, the described process of vegetational succession is repeated continuously as new lava destroys established vegetation on the surface (and the roots underneath), but also provides soon (within few years) new substrate for pioneering plants and consequently, new habitat for cavernicolous Oliarus. The dynamics of vegetational succession on the surface is closely correlated with the destruction and creation of planthopper habitat: fragmentation of populations by new lava and repeated colonization of newly available areas with adequate resources are likely to be the driving forces of diversification among $O$. "polyphemus" populations. Field observations corroborate these assumptions: in 1995, we discovered $O$. "polyphemus" individuals (nymphs and adults) in a lava tube within a 1974 lava flow of Mauna Ulu. The margin of the nearest adjacent vegetated area being about $200 \mathrm{~m}$ away, the surface about the cave was still very sparsely colonized by ferns and Metrosideros (Fig. 5). Thus, we can assume underground migration at a rate of ca. $10 \mathrm{~m} /$ year which corresponds with laboratory observations.

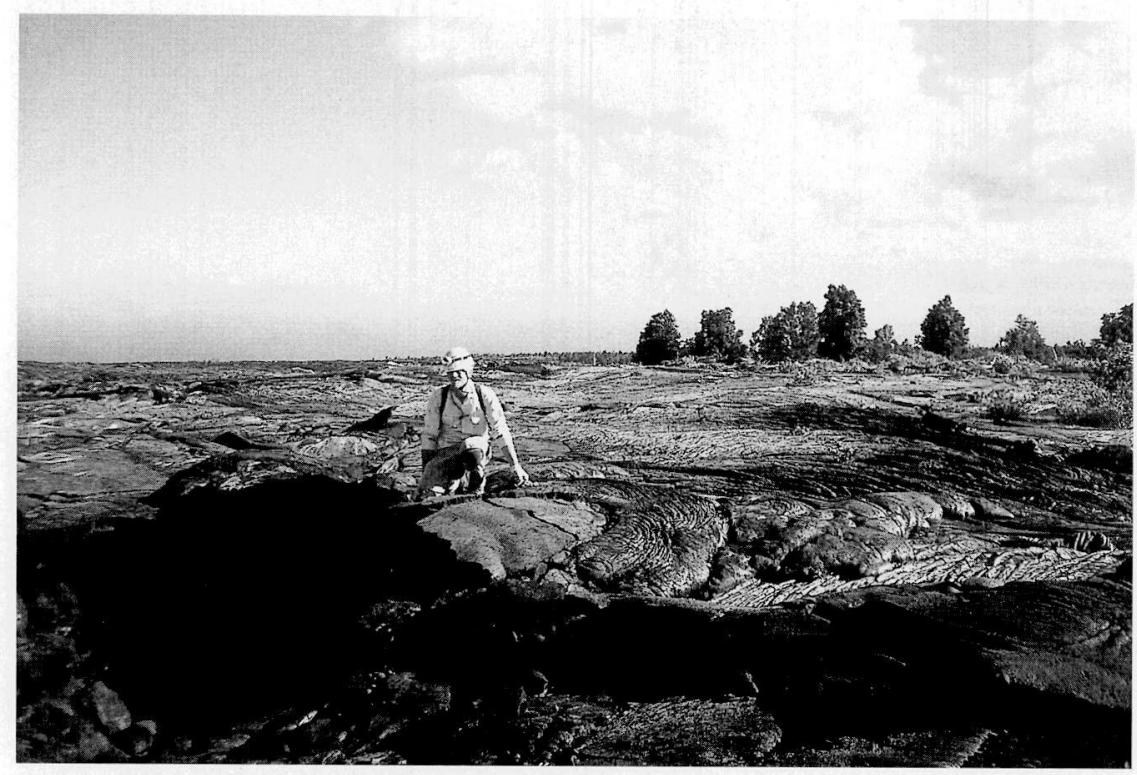

Fig. 5 - Lava field of Mauna Ulu: 1974 eruption. 


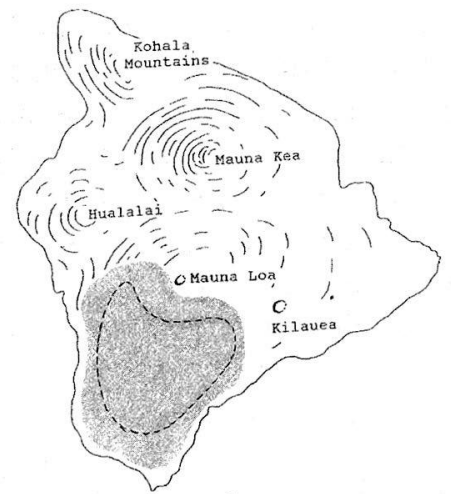

A

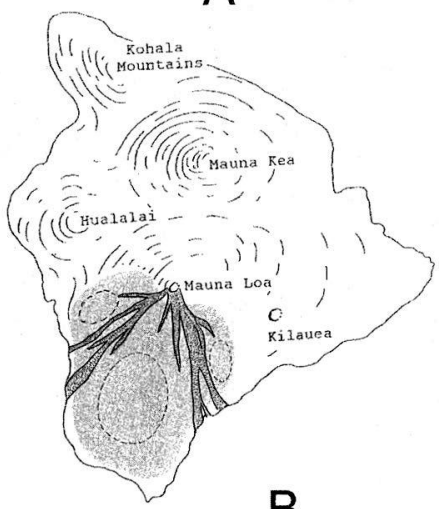

B

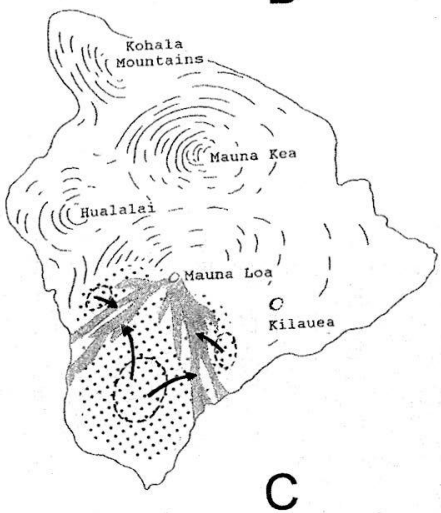

Fig. 6 - Hypothetic distribution of cave planthoppers and dynamics of their habitat in the course of vegetational succession on the surface. A. Grey-shaded area: distribution of suitable habitat; dash lines: range of a hypothetical rhizophageous cavernicolous species. B. Range fragmentation of ancestral population by new lava flows. C. Migration of cave planthoppers (arrows) following the distribution of their habitat: from areas under forest cover (black dots) to areas underneath adequately vegetated lava flows. 
It is conceivable that founder effects, small population size, and/or sexual selection facilitate rapid manifestation of differentiation (e.g., in regard to SMRS) acquired during separation. Upon secondary contact, these differentiations may act as factors in reproductive isolation. In the laboratory, secondary contact was simulated by playback experiments; in the field we have indications for sympatric occurence of two O. "polyphemus" species from only one lava tube (Pink Pistillaria Cave, Hualalai volcano) (Hoch and Howarth, 1993).

The hypothesis that active volcanism promotes speciation processes in cavernicoles is supported by observations on other islands in the Hawaiian chain: Maui and Molokai, both also comparatively young - and until quite recently volcanically active - islands, house cave planthopper species. On Oahu and Kauai, the geologically oldest of the "high" islands of Hawaii, erosion is far more progressed: accordingly, the extent of suitable habitat is much smaller, and no cave planthoppers have been found.

To test this hypothesis and to gain deeper insight in the mechanisms involved in incipient speciation, a population genetic study focussing on the phylogenetic relationship among select $O$. "polyphemus" taxa from various lava tubes is under way at the University of Missouri (K. Williamson). It is hoped that by using adequate genetic markers, we will learn to understand the evolutionary history of Oliarus. The information from the genetic studies can also be used to calibrate speciation events against geologic information, i.e., to determine evolutionary time.

\section{ACKNOWLEDGMENTS}

I would like to express my sincere thanks to Dr. Manfred Asche, Museum für Naturkunde, Berlin, for his support, his constructive criticism, and his never-fading enthousiasm in the field which kept me going through the tightest crawls. I also thank Dr. Frank Howarth, Bishop Museum, Honolulu, for fruitful discussions, continued stimulation and for his good humour which has highlighted many of our common field trips. Dr. Manfred Ade, Museum für Naturkunde, Berlin, kindly helped with image processing of figure 6. Last but not least I give a big mahalo to all the people in Hawaii who have in many ways contributed to this study, e.g. the staff of Bishop Museum, the University of Hawaii at Manoa and Hilo, The Nature Conservancy, Hawaii Volcanoes National Park, and private landowners for their support, their generous sharing of information and their trust that we might use it to help preserve one of Hawaii's most intriguing ecosystems.

\section{REFERENCES}

CLARIDE, M.F. 1985. Acoustic signals in the Homoptera: behavior, taxonomy, and evolution. Annual Review of Entomology 30: 297-317.

CARR, G.D. 1987. Beggar's ticks and tarweeds: masters of adaptive radiation. Trends in Ecology and Evolution, Special Issue: Hawaiian Evolutionary Biology, 2 (7): 192-195. 
FREED, L.A., CONANT, S. and FLEISCHER, R.C. 1987. Evolutionary ecology and radiation of Hawaiian Passerine birds. Trends in Ecology and Evolution, Special Issue: Hawaiian Evolutionary Biology, 2 (7): 196-203.

HARDY, D.E. 1974. Evolution in the Hawaiian Drosophilidae: 71-80. In: WHITE, M.J.D. (Ed.)-Genetic mechanisms of speciation in insects. Australia and New Zealand. Book Co., Sydney.

HOCH, H. and HOWARTH, F.G. 1993. Evolutionary dynamics of behavioral divergence among populations of the Hawaiian cave-dwelling planthopper Oliarus polyphemus (Homoptera: Fulgoroidea: Cixiidae). Pacific Science 47: 303-318.

HOLCOMB, R.T. 1987. Eruptive history and long-term behavior of Kilauea Volcano: 261350. In: DECKER, R.W., WRIGHT, T.L., STAUFFER, P.H. (Eds.)-Volcanism in Hawaii, vol.1. U.S.Geological Survey. Professional Paper no. 1350.

HOWARTH, F.G. 1972. Cavernicoles in lava tubes on the Island of Hawaii. Science 175: 325-326.

HOWARTH, F.G. 1983. Ecology of Cave Arthropods. Annual Review of Entomology 28: 365-389.

HOWARTH, F.G. 1991. Hawaiian cave faunas: macroevolution on young islands: 285-295. In: DUDLEY, E.C. (Ed.)-The unity of evolutionary biology. Vol. 1. Dioscorides Press, Portland, Oregon.

HOWARTH, F.G., HOCH, H., and ASCHE, M. 1990. Duets in darkness: species-specific substrate-borne vibrations produced by cave-adapted cixiid planthoppers in Hawaii (Homoptera: Fulgoroidea). Mémoires de Biospéologie 17: 77-80.

JUBERTHIE, C. 1983. Introduction, le milieu souterrain: etendue et composition. Mémoires de Biospéologie 10: 17-65.

LITTLEJOHN, M.J. 1988. The retrograde evolution of homogamic acoustic signaling systems in hybrid zones: 613-635. In: FRITZSCH, B. (Ed.) The evolution of the Amphibian Auditory System, John Wiley, New York.

LOCKWOOD, J.P. and LIPMAN, P.W. 1987. Holocene eruptive history of Mauna Loa volcano: 509-535. In: DECKER, R.W., WRIGHT, T.L. \& STAUFFER, P.H. (Eds.)Volcanism in Hawaii, vol.1. U.S.Geological Survey. Professional Paper no. 1350.

OSSIANNILSSON, F. 1949. Insect drummers. A study on the morphology and function of the sound-producing organ of Swedish Homoptera Auchenorrhyncha with notes on their sound production. Opusculae Entomologicae, Supplementum 10: 1-145.

OTTE, D. 1989. Speciation in Hawaiian crickets: 482 - 526. In: OTTE, D. and ENDLER, J.A. (Eds.) Speciation and its consequences. Sinauer Associates Inc., Sunderland, MA.

PATERSON, H.E.H. 1981. The continuing search for the unknown and unknowable: A critique of contemporary ideas on speciation. South African Journal of Science 77: 113-119.

PATERSON, H.E.H. 1985. The recognition concept of species: 21-30 In: VRYBA, E.S. (Ed.)-Species and Speciation. Transvaal Museum Monograph No. 4, Pretoria.

STRÜBING, H. and ROLLENHAGEN, T. 1988: Ein Aufnehmersystem für Vibrationssignale und seine Anwendung auf Beispiele aus der Familie Delphacidae (HomopteraCicadina). Zoologische Jahrbücher, Physiologie, 92: 245-268. 